\title{
The Effect of Oxatomide on Neutrophil Oxygen Radical Generation
}

\author{
Hirohiko Akamatsu, ${ }^{* a}{ }^{\text {Yoshiki Miyachi }},{ }^{b}$ Yasuo Asada, ${ }^{a}$ and Yukie Niwa ${ }^{c}$ \\ Department of Dermatology, Kansai Medical University, ${ }^{a} 1$ Fumizono-cho, Moriguchi, Osaka 570, Japan, Department \\ of Dermatology, Tenri Hospital, ${ }^{b}$ Tenri, Nara 632, Japan and Niwa Institute for Immunology, ${ }^{c}$ Tosashimizu, Kochi 787-03, \\ Japan. Received August 26, 1992
}

\begin{abstract}
The effect of oxatomide on reactive oxygen species (ROS) generated both by neutrophils and in a cell-free, xanthine-xanthine oxidase system was examined. The species investigated were superoxide radical anion $\left(\mathrm{O}_{2}^{-}\right)$, hydrogen peroxide $\left(\mathrm{H}_{2} \mathrm{O}_{2}\right)$ and hydroxyl radical $(\mathrm{OH} \cdot)$. Oxatomide significantly decreased neutrophil-generated $\mathrm{O}_{2}^{-}, \mathrm{H}_{2} \mathrm{O}_{2}$ and $\mathrm{OH} \cdot$ in a dose-dependent manner. $\mathrm{H}_{2} \mathrm{O}_{2}$ and $\mathrm{OH} \cdot$ generated in a cell-free system were also reduced in the presence of oxatomide.
\end{abstract}

The present study indicates that oxatomide decreases ROS generation presumably by inhibiting the neutrophil oxygen metabolism, and has the ability to scavenge $\mathrm{H}_{2} \mathrm{O}_{2}$ and $\mathrm{OH} \cdot$.

Keywords oxatomide; neutrophil; reactive oxygen species; anti-inflammatory effect

\section{Introduction}

Oxatomide (1-\{3-[4-(diphenylmethyl)-1-piperazinyl]propyl $\}$-1,3-dihydro-2 $H$-benzimidazol-2-one) is one of the orally active anti-allergic drugs. Oxatomide has clinically been demonstrated to have therapeutic efficacy in the treatment of allergic diseases such as allergic rhinitis, ${ }^{1)}$ chronic urticaria $^{2)}$ and asthma. ${ }^{3-5)}$ As its mechanisms of action, the inhibition of the effect as well as the release of allergic mediators such as histamine, ${ }^{6-8)}$ leukotrienes $^{7,9)}$ and platelet activating factor ${ }^{10,11)}$ have been reported.

Recently, reactive oxygen species (ROS) generated by neutrophils has been reported to be capable of causing tissue injury at the site of inflammation. It has been shown that oxatomide inhibits neutrophil-generated superoxide radical anion $\left(\mathrm{O}_{2}^{-}\right){ }^{12)}$ However, this result is not enough to evaluate the antioxidant action of the drug, because $\mathrm{O}_{2}^{-}$generation does not always reflect the effect of the drug on other ROS. It is, therefore, necessary to examine the effect on the level of all kinds of ROS, especially hydroxyl radical $(\mathrm{OH} \cdot)$ which is the most potent oxidant generated by neutrophils.

In the present study, we investigated the effect of oxatomide on the generation of ROS, including $\mathrm{O}_{2}^{-}$, hydrogen peroxide $\left(\mathrm{H}_{2} \mathrm{O}_{2}\right)$ and $\mathrm{OH} \cdot$, using both neutrophils and cell-free, xanthine-xanthine oxidase systems.

\section{Materials and Methods}

Chemicals Oxatomide (Kyowa Hakko Kogyo Co., Ltd., Tokyo, Japan) was added to the following assays measuring ROS generated both by neutrophils and by xanthine-xanthine oxidase system at concentrations of $0.05,0.5$ and $5.0 \mu \mathrm{g} / \mathrm{ml}$.

Neutrophil Preparation Neutrophils were isolated from heparinized venous blood from seven healthy volunteers by a modification of a previously described method. ${ }^{13)}$ After centrifugation of the blood which was set over a Ficoll-Hypaque gradient, the plasma-containing upper layer, mononuclear cell layer, and the remaining cell pellet were obtained. The plasma was freed of platelets by centrifugation. The cell pellet, containing neutrophils and erythrocytes, was washed with saline solution and resuspended in plasma containing dextran 170 (molecular weight, 170000) at a final concentration of $1 \%$. The neutrophils were recovered after sedimentation at unit gravity, and a few contaminating erythrocytes were lysed by treatment of the preparation with $0.88 \% \mathrm{NH}_{4} \mathrm{Cl}$. By this procedure, the viability of the harvested neutrophils was always greater than $99 \%$ by the trypan blue exclusion test, and $\left[{ }^{14} \mathrm{C}\right]$ inulin uptake, which measures phagocytic activity, was greater than $900 \mathrm{dpm} .{ }^{14)}$ The neutrophils were then resuspended in a medium appropriate for their subsequent use: Krebs Ringer phosphate (KRP) containing glucose $(5 \mathrm{mM})$ for $\mathrm{OH}$. generation; and KRP buffer containing glucose $(5 \mathrm{~mm})$ and gelatin $(1 \mathrm{mg} / \mathrm{ml})$ for the assaying of $\mathrm{O}_{2}^{-}$and $\mathrm{H}_{2} \mathrm{O}_{2}$ generation.

Viability and Phagocytic Function of Neutrophils Neutrophil viability after incubation with an agent was determined by trypan-blue exclusion; phagocytic functions were measured by zymosan-induced stimulation of $\left[{ }^{14} \mathrm{C}\right]$ inulin uptake. ${ }^{14)}$ When over $2 \%$ of the neutrophils were stained by trypan-blue, or when neutrophils showed less than $600 \mathrm{dpm}\left[{ }^{14} \mathrm{C}\right]$ inulin uptake/mg protein, their function was considered to have been impaired and the results were discarded.

Neutrophil ROS Generation Assays In studies of $\mathrm{O}_{2}^{-}$formation, $1 \times 10^{6}$ neutrophils were preincubated at $37^{\circ} \mathrm{C}$ for $10 \mathrm{~min}$ with $1 \mathrm{mg} / \mathrm{ml}$ opsonized zymosan (Sigma), then $0.1 \mathrm{~mm}$ ferricytochrome c (type III, Sigma) was added. The neutrophils were incubated for another $30 \mathrm{~min}$. Immediately after sedimentation of the neutrophils and opsonized zymosan by centrifugation, $0.1 \mathrm{ml}$ of the supernatant was assayed for reduced cytochrome $\mathrm{c}$ by measuring absorbance at $550 \mathrm{~nm}^{15,16)}$ in $2 \mathrm{ml}$ of $100 \mathrm{~mm}$ potassium phosphate buffer ( $\mathrm{pH} 7.8$ ) containing 0.1 mM EDTA ( $\mathrm{pH} 7.8$ ). The results were converted to nmol of reduced cytochrome $\mathrm{c}$, using $\Delta E_{550}=2.1 \times 10^{4} / \mathrm{M} / \mathrm{cm} .{ }^{17)} \mathrm{SOD}$ (Sigma) also was added to the neutrophil medium at a concentration of 400 units $/ \mathrm{mI}$ to inhibit the reduction of cytochrome c by $\mathrm{O}_{2}^{-}$.

$\mathrm{H}_{2} \mathrm{O}_{2}$-generation was measured by quantifying the decrease in fluorescence intensity of scopoletin (Sigma) due to its peroxidase-mediated oxidation by $\mathrm{H}_{2} \mathrm{O}_{2}{ }^{1{ }^{17)}}$ After incubation of $2.5 \times 10^{6}$ neutrophils for $10 \mathrm{~min}$ at room temperature in KRP containing $5 \mathrm{~mm}$ glucose and $0.1 \mathrm{mg} / \mathrm{ml}$ gelatin in the presence of $1 \mathrm{mg} / \mathrm{ml}$ opsonized zymosan, $0.1 \mathrm{ml}$ of $50 \mathrm{~mm}$ scopoletin in KRP and $0.05 \mathrm{ml}$ of $1 \mathrm{mg} / \mathrm{ml}$ horseradish peroxidase (type II; Sigma) in phosphate-buffered saline (PBS) were added. The rate of decrease in fluorescence intensity of the scopoletin was quantified using a fluorescence spectrophotometer (Hitachi Co., Ltd., Tokyo, Japan). To calculate $\mathrm{H}_{2} \mathrm{O}_{2}$ concentration, we assumed that $1 \mathrm{~mol}$ of $\mathrm{H}_{2} \mathrm{O}_{2}$ oxidized I mol of scopoletin. ${ }^{17)}$ Incubation of supernates with an excess of 400 units $/ \mathrm{ml}$ catalase (Sigma) inhibited fluorescence reduction.

$\mathrm{OH}$ - was quantitated by the amount of ethylene formed from $\alpha$-keto-methiolbutyric acid (KMB) (Sigma) plus $\mathrm{OH} \cdot$ generated by neutrophils. ${ }^{18)}$ Neutrophils $\left(2 \times 10^{6}\right)$ in $2 \mathrm{ml} \mathrm{KRP}$ containing glucose were preincubated with $1 \mathrm{mM} \mathrm{KMB}$ in a stoppered tube and gently mixed in a $37^{\circ} \mathrm{C}$ shaker bath for $5 \mathrm{~min}$. Opsonized zymosan was then added, and the cells were incubated for $10 \mathrm{~min}$. Thereafter, aliquots of gas in the tube were sampled using a gas-tight syringe, and the ethylene content was determined by a gas chromatography (Hitachi). The total amount of ethylene formed during 10,20 and $30 \mathrm{~min}$ served as the $\mathrm{OH}$ - value.

ROS Generation Assay in the Xanthine-Xanthine Oxidase System All ROS were also measured in the xanthine-xanthine oxidase system. Instead of adding neutrophils and opsonized zymosan, $0.1 \mathrm{~mm}$ hypoxanthine, $1.25 \mathrm{~mm}$ EDTA and $16.5 \mu \mathrm{m}$ ferricytochrome $\mathrm{c}$ were added to make a total volume of $2 \mathrm{ml}$ ( $125 \mathrm{~mm}$ phosphate buffer). After the addition of the various concentrations of oxatomide, approximately $0.006 \mathrm{U} / \mathrm{ml}$ of dialyzed xanthine oxidase was added to generate ROS. ${ }^{19}$ )

Triplicate assays were performed in each experiment; the results are expressed as the mean \pm S.D. of replicate assays. Statistical significance was ascertained by Student's $t$-test. 


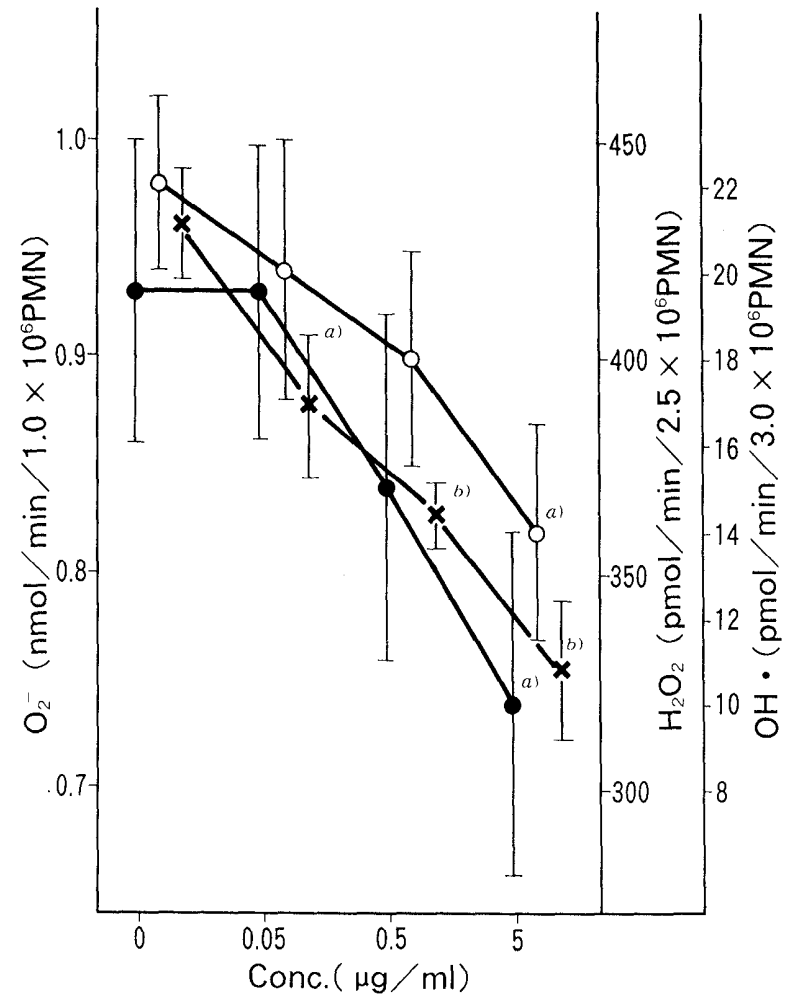

Fig. 1. Effect of Oxatomide on ROS Generation by Neutrophils

Closed circle (O) denotes $\mathrm{O}_{2}^{-}$, open circle $(\mathrm{O}) \mathrm{H}_{2} \mathrm{O}_{2}$, and cross symbol $(x) \mathrm{OH}$ levels, respectively. PMN denotes polymorphonuclear leukocytes. a) $p<0.05$ vs. control, b) $p<0.01$.

\section{Results}

Oxatomide significantly decreased $\mathrm{O}_{2}^{-}, \mathrm{H}_{2} \mathrm{O}_{2}$ and $\mathrm{OH} \cdot$ generated by human neutrophils, respectively $\left(\mathrm{O}_{2}^{-}: 21.2 \%\right.$ inhibition by $5 \mu \mathrm{g} / \mathrm{ml}, p<0.05, \mathrm{H}_{2} \mathrm{O}_{2}: 20.2 \%$ inhibition by $5 \mu \mathrm{g} / \mathrm{ml}, p<0.05, \mathrm{OH} \cdot: 20.4 \%$ inhibition by $0.05 \mu \mathrm{g} / \mathrm{ml}$, $p<0.05 ; 25.4 \%$ inhibition by $0.5 \mu \mathrm{g} / \mathrm{ml}$; and $50.1 \%$ inhibition by $5 \mu \mathrm{g} / \mathrm{ml}, p<0.01$ ) (Fig. 1). $\mathrm{H}_{2} \mathrm{O}_{2}$ and $\mathrm{OH} \cdot$ generated in a xanthine-xanthine oxidase system were also reduced in the presence of oxatomide $\left(\mathrm{H}_{2} \mathrm{O}_{2}: 17.1 \%\right.$ inhibition by $0.5 \mu \mathrm{g} / \mathrm{ml}, p<0.05 ; 22.5 \%$ inhibition by $5 \mu \mathrm{g} / \mathrm{ml}, p<0.01, \mathrm{OH} \cdot: 20.0 \%$ inhibition by $0.5 \mu \mathrm{g} / \mathrm{ml}$, $p<0.05 ; 32.1 \%$ inhibition by $5 \mu \mathrm{g} / \mathrm{ml}, p<0.01)$. However, $\mathrm{O}_{2}^{-}$generated by xanthine-xanthine oxidase was not decreased by any dose of oxatomide $(p>0.05)$ (Fig. 2).

\section{Discussion}

Oxatomide significantly decreased the neutrophil-induced ROS, which is one of the most potent inflammatory mediators. The drug showed an especially marked reduction of the most toxic $\mathrm{OH}$ - at concentrations almost comparable to blood levels in man after a long period of oral administration of therapeutic dose. $\mathrm{H}_{2} \mathrm{O}_{2}$ and $\mathrm{OH}$. generated by xanthine-xanthine oxidase system, furthermore, were reduced in the presence of oxatomide. Taniguchi et al. ${ }^{12)}$ previously demonstrated that oxatomide reduces the neutrophil-generated $\mathrm{O}_{2}^{-}$, and this was confirmed by the results of the present investigation. Our results indicate that oxatomide decreases ROS generation presumably by inhibiting the neutrophil oxygen metabolism, and has the ability to scavenge $\mathrm{H}_{2} \mathrm{O}_{2}$ and $\mathrm{OH} \cdot$.

It has been reported that ROS are closely correlated with the pathogenesis of a variety of inflammatory skin diseases

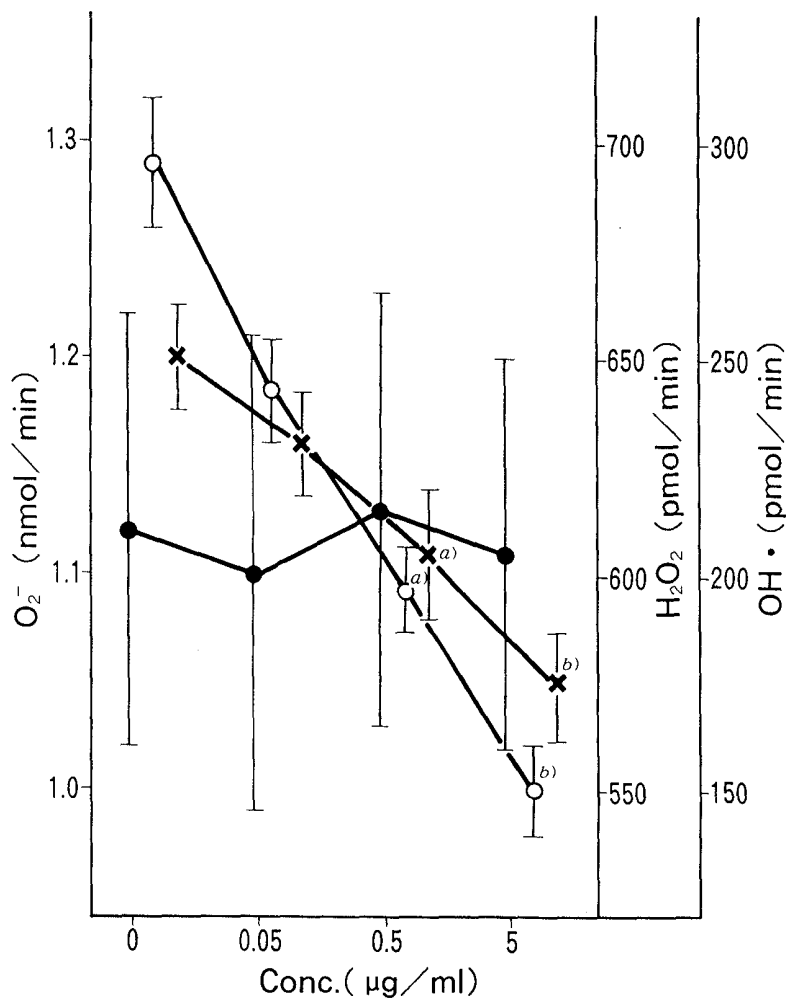

Fig. 2. Effect of Oxatomide on ROS Generated in the XanthineXanthine Oxidase System

For other symbols: see legend for Fig. 1.

such as linear IgA bullous dermatosis, psoriasis, leukocytoclastic vasculitis and Behçet's disease. ${ }^{13,20-22)}$ Some drugs exert anti-inflammatory action by reducing the ROS generated by neutrophils. ${ }^{23-25)}$

Our results demonstrate that oxatomide markedly decreases $\mathrm{O}_{2}^{-}, \mathrm{H}_{2} \mathrm{O}_{2}$ and $\mathrm{OH} \cdot$ generated by neutrophils. $\mathrm{H}_{2} \mathrm{O}_{2}$ and $\mathrm{OH} \cdot$ generated by xanthine-xanthine oxidase system were also reduced in the presence of the drug. Oxatomide has an anti-inflammatory effect presumably due to its antioxidant action. Our study provides an additional theoretical basis for oxatomide therapy in allergic diseases complicated with inflammation induced by ROS in tissues and organs.

\section{References}

1) E. F. Juniper, A. Cartier, A. L. Trebilcock, P. A. Frith, J. Dolovich, and F. E. Hargreave, Clin. Allergy, 11, 61 (1981).

2) P. Dockx, J. Vertommen, R. V. Daele, and J. D. Weert, Curr. Ther. Res., 29, 510 (1981)

3) S. W. Banhan and F. Moran, Br. J. Clin. Pract., 34, 323 (1980).

4) J. D. E. Cree, H. Verhaegen, H. Geukens, and J. Streumers, Clin. Trial J., 17, 84 (1980).

5) M. Silverman and M. Tooley, Clin. Allergy, 11, 421 (1981).

6) F. D. Clerck, V. Reempts, and M. Borgers, Agents Actions, 11, 184 (1981).

7) K. Ohmori, H. Ishii, T. Kubota, K. Shuto, and K. Nakamizo, Arch. Int. Pharmacodyn. Ther., 275, 139 (1985).

8) K. Tasaka, M. Akagi, M. Mio, K. Miyoshi, and N. Nakaya, Int. Arch. Allergy Appl. Immunol., 83, 348 (1987).

9) H. Manabe, K. Ohmori, H. Tomioka, and H. Yoshida, Int. Arch. Allergy Appl. Immunol., 87, 91 (1988).

10) F. P. Nijkamp, G. Folkerts, J. R. Beetens, and F. D. Clerck, Naunyn-Schmiedeberg's Arch. Pharmacol., 340, 111 (1989).

11) Y. Toku, K. Hayashi, K. Nagano, Y. Tsujimoto, M. Youi, and Y. Tsuji, Allergy No Rinsho, 9, 831 (1989).

12) K. Taniguchi, Y. Masuda, and K. Takanaka, Jpn. J. Pharmacol., 52, 101 (1990) 
13) Y. Niwa, T. Sakane, M. Shingu, I. Yanagida, J. Komura, and Y. Miyachi, Arch. Dermatol., 121, 73 (1985).

14) J. L. Skosey, E. Damgaard, D. C. Chow, and L. B. Sorensen, J. Cell Biol., 62, 625 (1974).

15) R. B. Johnston, Jr. and J. E. Lehmeyer, J. Clin. Invest., 57, 836(1976).

16) V. Massey, Biochim. Biophys. Acta, 34, 255 (1959).

17) R. K. Root and J. A. Metcalf, J. Clin. Invest., 60, 1266 (1972)

18) S. J. Klebanoff and H. Rosen, J. Exp. Med., 148, 490 (1978).

19) Y. Niwa, T. Kasama, Y. Miyachi, and T. Kanoh, Life Sci., 44, 1655 (1989).

20) Y. Miyachi and Y. Niwa, Arch. Dermatol. Res., 275, 23 (1983).
21) Y. Miyachi, K. Yanase, S. Imamura, and Y. Niwa, Arch. Dermatol. Res., 274, 65 (1982).

22) Y. Niwa, S. Miyake, T. Sakane, M. Shingu, and M. Yokoyama, Clin. Exp. Immunol., 49, 247 (1982).

23) H. Akamatsu, M. Oguchi, S. Nishijima, Y. Asada, M. Takahashi, T. Ushijima, and Y. Niwa, Arch. Dermatol. Res., 282, 449 (1990).

24) H. Akamatsu, Y. Komura, Y. Asada, Y. Miyachi, and Y. Niwa, Arch. Dermatol. Res., 283, 162 (1991).

25) H. Akamatsu, J. Komura, Y. Asada, and Y. Niwa, Planta Medica, 57, 119 (1991). 